\title{
Walking Speed Modeling on Transfer Passengers in Subway Passages
}

\author{
Zhijie Chen $^{1, a}$, Xinmiao Zhao ${ }^{1, b}$ and Ruijia Shi ${ }^{1, c}$ \\ ${ }^{1}$ MOE Key Laboratory for Urban Transportation Complex Systems Theory and Technology, Beijing \\ Jiaotong University, Beijing 100044 \\ achen2640@bjtu.edu.cn, ${ }^{\mathrm{b}}$ zhaoxm@bjtu.edu.cn, c shiruijia@bjtu.edu.cn
}

Keywords: Subway; Transfer station; Passenger; Individual characteristics; Walking speed.

Abstract. Accurate measurement of passengers' walking speed is significant for evaluating and optimizing service level of the facilities in transfer stations. This paper studies the walking speeds of various transfer passengers on the upstairs of Beijing Haidian Huangzhuang Subway Station during evening peak hours by statistical analysis. The results show that the walking speeds of the male, the middle-aged and the crowed passengers all follow Log-normal distribution. During evening peak hours the passengers' walking speeds on the upstairs in subway are a bit faster, but the speeds are still limited by the capacity of the facilities.

\section{Introduction}

Subway plays an important role in urban public transport and attracts more attention with rapid growth. Since the subway has been built into a network, passengers' demand gradually increases in subway. However, lack of capacity of facilities and low service level are unable to meet the requirements of passengers. Reasonable design of the transfer facilities is important to the capacity of facilities in subway. Facilities affect the service level and should be designed by considering passenger perceptions.

The current researches have studied some influential factors of walking speeds. Literature [1] and [2] studied the factors by qualitative analysis. Literature [3] studied the walking speeds of people who run a red light. Literature [4] studied the influence of baggage on the walking speeds of passengers in an airport. Literature [5] and [6] studied the transfer passengers by simulation with the maximum walking speed. Therefore, the walking speeds of different passengers need further research under different situations of facilities.

\section{Data survey and analysis of influential factors}

The influential factors of walking speeds of passengers in transfer facilities include gender, age, luggage, whether companied and the degree of crowding. Through field observations in Beijing Haidian Huangzhuang Subway Station, which is a transfer station of Line 4 and Line 10 with large transfer passenger flow, we find few passengers taking large baggage. Male passengers walk faster than female passengers, especially on upstairs. There are more young and middle-aged passengers than the elder and children. Passengers companied walk slower than passengers alone. Therefore we only consider passengers without baggage, the young and the middle-aged passengers. The degree of crowding is divided into three types: smooth, slight congestion and heavy congestion. Smooth means passengers can travel freely in accordance with their wishes; slight congestion means passengers can bypass the passengers in front with faster speeds although there're more passengers in the facilities; heavy congestion refers to the situation that passengers can't bypass the passengers in front.

Firstly, the study time is designed as 17:00 to 19:30 in the evening peak hours. We survey the walking speeds of passengers on the upstairs transferring from Line 4 to Line 10, and distinguish them into male and female. Secondly, we calculate the other factors. Eventually, the walking speeds of passengers with different properties are shown in Table 1 and the histogram of the survey data is simply fitted to a distribution density curve shown in Figure 1. 
Table 1 The average walking speed of passengers on upstairs with different properties

\begin{tabular}{|c|c|c|c|c|}
\hline $\begin{array}{l}\text { Influential } \\
\text { factors }\end{array}$ & Categories & $\begin{array}{l}\text { Average walking } \\
\text { speed on slopes in } \\
\text { transferring }(\mathrm{m} / \mathrm{s})\end{array}$ & $\begin{array}{l}\text { Average horizontal } \\
\text { walking speed in } \\
\text { transferring }(\mathrm{m} / \mathrm{s})\end{array}$ & $\begin{array}{l}\text { Standard } \\
\text { deviation }\end{array}$ \\
\hline \multirow{2}{*}{ Gender } & Male & 0.90 & 0.82 & 0.359 \\
\hline & Female & 0.71 & 0.65 & 0.129 \\
\hline \multirow{2}{*}{ Age } & Young & 0.84 & 0.77 & 0.289 \\
\hline & Middle-aged & 0.69 & 0.63 & 0.122 \\
\hline \multirow{2}{*}{$\begin{array}{l}\text { Whether } \\
\text { companied }\end{array}$} & Companied & 0.61 & 0.56 & 0.063 \\
\hline & Single & 0.82 & 0.75 & 0.260 \\
\hline \multirow{3}{*}{$\begin{array}{l}\text { Degree of } \\
\text { crowding }\end{array}$} & Smooth & 0.86 & 0.79 & 0.321 \\
\hline & Slight congestion & 0.72 & 0.66 & 0.138 \\
\hline & Heavy congestion & 0.67 & 0.61 & 0.093 \\
\hline & Total & 0.79 & 0.72 & 0.236 \\
\hline
\end{tabular}

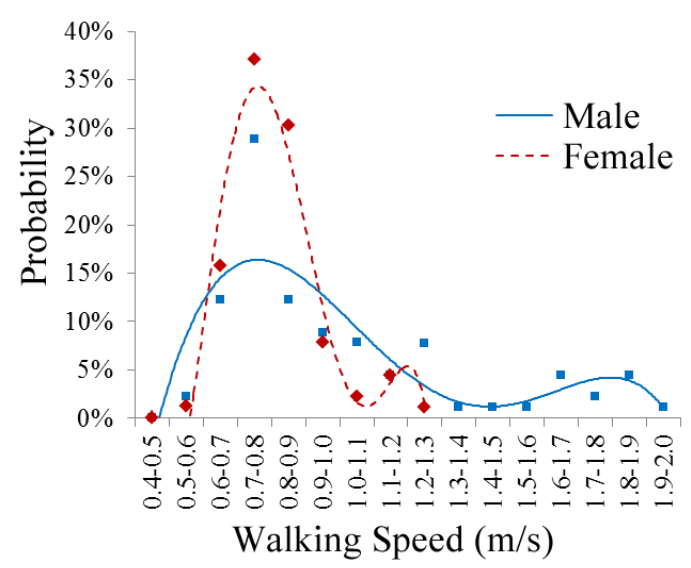

(a) Gender

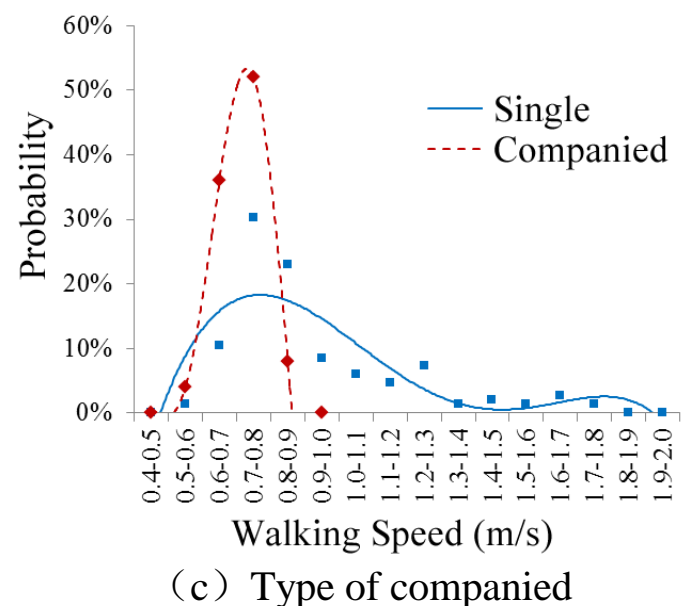

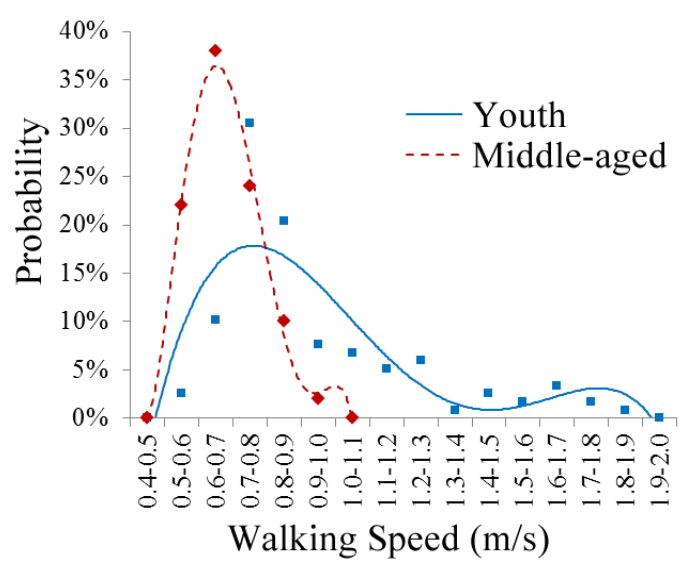

(b) Age

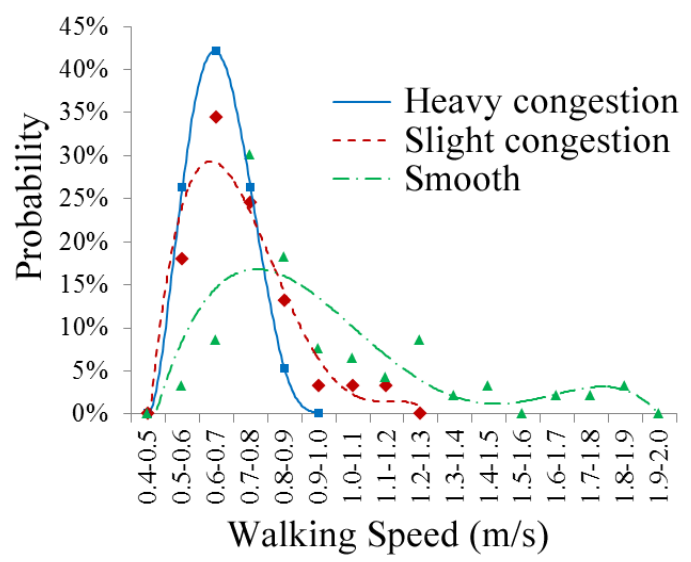

(d) Degree of congestion

Fig. 1 The distribution density curve of passengers' walking speeds on upstairs

\section{Data analysis}

The survey data are tested by the method of goodness-of-fit to study the distribution of passengers' walking speeds in different situations, and this paper compares the influence of different factors on passengers' walking speeds. 
Figure. 1 shows the characteristics of passengers' walking speeds as follows:

(1) The distribution curves show obvious peaks and left-right asymmetry. When passengers' walking speeds increases, the frequency increases sharply to reach a peak and then it decreases slowly, which means that the walking speeds follow some rules and the walking speeds are limited by the capacity of the facilities.

(2) There're some local optimal solutions on the curve, which means the individual characteristics and environmental factors have an obvious impact on the walking speeds of passengers.

According to the above analysis, Kolmogorov-Smirnov test is applied to measure the correlation between the Log-normal distribution function and the survey data with the passenger properties: male, middle-aged, and heavy congestion. The correlation of Kolmogorov-Smirnov test is significant at 0.05 . SPSS software is used in the test and the correlation coefficients of these three passenger properties are respectively $0.055,0.228$ and 0.597 , which indicates a stronger correlation.

The walking speed distribution density functions of passengers on upstairs are shown in Table 2. The maximum likelihood estimation method is used to estimate the mean $\mu$ and the variance $\sigma$.

Table 2 The walking speed distribution density functions of passengers on upstairs

\begin{tabular}{cccc}
\hline $\begin{array}{c}\text { Type of } \\
\text { passengers }\end{array}$ & \multicolumn{2}{c}{ The distribution function of walking speed } & \multicolumn{2}{c}{ Parameters } \\
\cline { 3 - 4 } Male & $f(x, \mu, \sigma)=\frac{1}{\sqrt{2 \pi \times(0.37943)^{2}}} \exp \left[-(\operatorname{In} x+0.1265)^{2} / 2 \times(0.37943)^{2}\right]$ & -0.1265 & 0.37943 \\
Middle-aged & $f(x, \mu, \sigma)=\frac{1}{\sqrt{2 \pi \times(0.15939)^{2}}} \exp \left[-(\operatorname{In} x+0.3747)^{2} / 2 \times(0.15939)^{2}\right]$ & -0.3747 & 0.15939 \\
$\begin{array}{c}\text { Heavy } \\
\text { congestion }\end{array}$ & $f(x, \mu, \sigma)=\frac{1}{\sqrt{2 \pi \times(0.18898)^{2}}} \exp \left[-(\operatorname{In} x+0.3650)^{2} / 2 \times(0.18898)^{2}\right]$ & -0.365 & 0.18898 \\
\hline
\end{tabular}

In general, the walking speed varies with individual characteristics and environmental conditions, and the figures show some results as follows:

(1) As can be seen from Table 1, male, young and single passengers usually walk faster, because male passengers and young passengers are better at physical conditions. Female passengers and the middle-aged passengers care more about safety, and the passengers companied usually talk with each other. Walking speeds are slower when the passengers are in congestion, because the upward and downward passengers mix together on the stairs, which lead to interference.

(2) The variances of the male, the young and the single passengers' walking speeds are less than that of the female, the middle-aged passengers and the passengers companied, because the female and the middle-aged are limited by physical conditions, also the passengers companied are not in hurry.

The relationships between passengers' walking speeds with different characteristics and environmental conditions are analyzed by multiple linear regressions according to the characteristics concluded earlier.

The passengers' walking speed is regarded as the dependent variable Y. Gender $\mathrm{X}_{1}$ (male: 1, female: 0 ), age $X_{2}$ (youth: 1, middle-aged: 0), type of companied $X_{3}$ (single: 1, companied: 0), degree of congestion $\mathrm{X}_{4}$ (smooth: 0, slight congestion: 1, heavy congestion: 0), degree of congestion $\mathrm{X}_{5}$ (smooth: 1, slight congestion and heavy congestion: 0 ) are regarded as main influential factors.

SPSS software is used in multivariate linear regression analysis. The results are shown in Table 3. All the significant levels of the main factors are less than 0.05 , which indicates that the factors all have important effects on passengers' walking speeds. 
Table 3 Result of the coefficients

\begin{tabular}{|c|c|c|c|c|c|c|c|}
\hline \multirow{2}{*}{ Model } & \multicolumn{2}{|c|}{$\begin{array}{l}\text { Unstandardized } \\
\text { Coefficients }\end{array}$} & \multirow{2}{*}{$\begin{array}{c}\text { Standardized } \\
\text { Coefficients } \\
\text { Beta }\end{array}$} & \multirow[t]{2}{*}{$\mathrm{t}$} & \multirow{2}{*}{ Sig. } & \multicolumn{2}{|c|}{ Correlations } \\
\hline & B & Std. Error & & & & Zero order & VIF \\
\hline (Constant) & 0.286 & 0.019 & & 15.108 & 0.001 & & \\
\hline Gender & 0.190 & 0.014 & 0.477 & 13.171 & 0.001 & 1.000 & 1.000 \\
\hline Age & 0.150 & 0.014 & 0.401 & 11.024 & 0.002 & 0.994 & 1.006 \\
\hline Whether companied & 0.215 & 0.012 & 0.639 & 17.554 & 0.000 & 0.991 & 1.010 \\
\hline Crowding1 & 0.053 & 0.014 & 0.155 & 3.782 & 0.032 & 0.787 & 1.271 \\
\hline Crowding2 & 0.196 & 0.013 & 0.602 & 14.697 & 0.001 & 0.781 & 1.280 \\
\hline
\end{tabular}

A multivariate linear regression equation is obtained from Table 3 as follows:

$Y=0.286+0.190 X_{1}+0.150 X_{2}+0.215 X_{3}+0.053 X_{4}+0.196 X_{5}$

The standardized regression equation is:

$Y=0.477 X_{1}+0.401 X_{2}+0.639 X_{3}+0.155 X_{4}+0.602 X_{5}$

In summary, the most significant factor is whether the passenger is companied, followed by the degree of congestion in facilities, gender and age.

\section{Comparison with other researches}

The walking speeds of passengers in transfer facilities studied by other researchers are shown in Table 4, in which the horizontal speed on upstairs is $0.72 \mathrm{~m} / \mathrm{s}$ and downstairs is $0.74 \mathrm{~m} / \mathrm{s}$.

Compared with Literature [7], which concluded the walking speed on slope in Hong Kong Subway is $0.97-1.01 \mathrm{~m} / \mathrm{s}$, the walking speed in this paper is $0.79 \mathrm{~m} / \mathrm{s}$ because of the serious mutual interference caused by the upward and downward passengers on the stairs.

The walking speeds of male, female, young and middle-aged passengers are close to the results of Galea [8], and they are larger than that of Nanjing pedestrian tunnel stairs in Literation [9] and Beijing Dongdan Subway Station in Line 5 in Literation [10], for the reason that Haidian Huangzhuang Station is located in Zhongguancun High-tech Park, and the young passengers who take a large proportion of the transfer flow are similar to Europeans on physical conditions.

Table 4 Comparison on walking speeds of passengers in other studies

\begin{tabular}{|c|c|c|c|}
\hline Researcher & Scenario & Type of passengers & Walking speed $(\mathrm{m} / \mathrm{s})$ \\
\hline \multirow{4}{*}{ Galea et al. $(2004)^{[8]}$} & \multirow{4}{*}{ buildingEXODUS 4.0} & Young male & 0.84 \\
\hline & & Young female & 0.70 \\
\hline & & Middle-aged male & 0.74 \\
\hline & & Middle-aged female & 0.63 \\
\hline \multirow{4}{*}{$\begin{array}{l}\text { Traffic Engineering } \\
\text { Handbook }(1998)^{[9]}\end{array}$} & \multirow{4}{*}{$\begin{array}{l}\text { Pedestrian tunnel in } \\
\text { Nanjing }\end{array}$} & Young male & 0.79 \\
\hline & & Young female & 0.60 \\
\hline & & Middle-aged male & 0.66 \\
\hline & & Middle-aged female & 0.57 \\
\hline \multirow{4}{*}{$\mathrm{Xu}(2008)^{[10]}$} & \multirow{2}{*}{$\begin{array}{c}\text { Dongdan Subway Staion } \\
\text { in Beijing }\end{array}$} & Male & 0.70 \\
\hline & & Female & 0.62 \\
\hline & \multirow{2}{*}{$\begin{array}{l}\text { Xizhimen Subway Staion } \\
\text { in Beijing }\end{array}$} & Male & 0.66 \\
\hline & & Female & 0.58 \\
\hline \multirow{4}{*}{ This paper } & \multirow{4}{*}{$\begin{array}{l}\text { Haidian Huangzhuang } \\
\text { Subway Staion in Beijing }\end{array}$} & Male & 0.82 \\
\hline & & Female & 0.65 \\
\hline & & Young & 0.77 \\
\hline & & Middle-aged & 0.63 \\
\hline
\end{tabular}




\section{Conclusions}

This paper surveys the walking speeds of passengers in different situations at Haidian Huangzhuang Subway Station, and the conclusions are as follows:

(1) The walking speeds of young passengers, middle-aged passengers, and passengers in heavy congestion on upstairs proximately follow Log-normal distribution;

(2) Walking speeds are significantly affected by passengers' individual characteristics and transfer facilities, and the influential factors are ordered by their importance as follows: whether companied, the degree of congestion, gender and age.

(3) The walking speeds of passengers on upstairs at Haidian Huangzhuang Subway Station during the evening peak hours are limited by the capacity of facilities.

\section{Acknowledgements}

The authors are grateful to the National Basic Research Program (2012CB725406), the National Natural Science Foundation $(71131001,71390332)$ of China for their supports on this work. The authors also thank the anonymous reviewers and the editor for their suggestions to improve this paper.

\section{References}

[1] J.F. Liu, F.L. Sun, Y Bai and X.U. Juan: Journal of Transportation Systems Engineering \& Information Technology Vol. 9-2 (2009), p. 81-86.

[2] S.C. Tang: Railway Transport and Economy Vol. 29-9 (2007), p. 48-49.

[3] W.H.K Lam, J.F. Morrall and H. Ho: Transp. Res. Record Vol. 1487 (1995), p. 56-62.

[4] S.B. Young: Transp. Res. Record Vol. 1 (1999), p. 20-26.

[5] R.L. Hughes: Transp. Res. Part B Methodological Vol. 36-6 (2002), p. 507-535.

[6] R.Y. Guo, S.C. Wong, H.J. Huang, P. Zhang and W.H.K. Lam: Physica A Statistical Mechanics \& Its Applications Vol. 389-3 (2010), p. 515-526.

[7] W.H.K. Lam: Journal of Transportation Engineering Vol. 126-4 (2000), p. 343-349.

[8] E.R. Galea, S. Gwynne, P. Lawrence, L. Filippidis and D. Blackshields: User Guide and Technical Manual for buildingEXODUS (University of Greenwich, U.K. 2004).

[9] China Highway Society of Traffic Engineering Handbook Editorial Board: Transportation Engineering (China Communications Press, China 1998).

[10]Q.W. Xu: Master Degree Thesis (Beijing Jiaotong University, China 2008). 